\title{
The Layout Characteristic Changes of Ancient Pagoda of the Liao and Jin Dynasty from Golden and Silver Pagoda in Shimu Town Haicheng City
}

\author{
$\mathrm{Ni}$ Xin \\ Harbin University of Commerce, Harbin 150028, China \\ MAME2013@163.com
}

Keywords: Liao pagoda, Jin pagoda, layout, multi-eaved pagoda, dougong.

\begin{abstract}
There are many pagoda remains of the Liao and Jin dynasty in the northern area of China. There are two very distinctive ancient pagodas located in the Shimu Town, Haicheng City, Liaoning Province. The "golden pagoda" with large volume was built in the Liao Dynasty; slightly smaller "Silver pagoda" was built in the Jin Dynasty. More simply, the two pagodas are northern solid multi-eaved brick pagoda, the structure are all composed of the pagoda foundation, pagoda body, pagoda eaves three parts. But if we carefully observe them, we will find very big differences between the two.
\end{abstract}

\section{Introduction}

There are many ancient pagoda remains of Liao and Jin Dynasty in the northern area of China. There are two very distinctive ancient pagodas located in the Shimu Town, Haicheng City, Liaoning Province. These two ancient pagodas are not famous compared with Jinzhou Baita, Yixian Guangshengsi pagoda, Chaoyang north and south pagoda, but the unique charm of these two pagodas make the people who know them always linger on with no thought of leaving. For hundreds of years, they have stood quietly and looked forward to a glimpse of passing travellers. The two pagodas, the "golden pagoda" with large volume was built in the Liao Dynasty, slightly smaller "Silver pagoda" was built in the Jin Dynasty. Although they belong to the Liao, Jin multi-eaved pagoda system, the shapes are different. We can just sum up different characteristics of pagoda of Liao and Jin Dynasty according to the different layouts of the two pagodas. What are these two pagodas look like? First of all, we have to understand the shapes of the two pagodas.

\section{Basic Layout Characteristics of the Shimu Golden and Silver Pagodas}

\subsection{Basic layout of the Shimu golden pagoda}

The Shimu golden pagoda is located in the western hillside of the horn mountain and is $2.5 \mathrm{~km}$ away from the Shimu town, the height of the pagoda is 31.5 meters, which is the octagonal thirteen-story solid eaves brick pagoda. (See Fig.1) The base part of the pagoda consists of bottom base and Xumizuo throne. The bottom base is repaired by descendants. A layer of waist of the Xumizuo throne is divided into two parts by instrument sculpture. Each part is open the pot door (the outline is similar to the blank door of pot). There are beautiful figure statues inside and outside pot door, but they have been damaged. Each corner of the waist where slave kneeling support the above double layer of upturned lotus, but the head is also damaged. The above of upturned lotus of pagoda is the double layer of waist supported by octagonal platform. The height of this layer of waist is about twice the height of one layer, it has only one pot door in each side, and there are prostrate lions head out the door in pot doors. The modeling of the lion are unusually vivid, twisting motion of each lion is different and grisly. (see Fig.2), practice of this prostrate lion of pot door, which can find only three cases in our country currently, there are Yixian Guangsheng pagoda, Zhongjing Jin small pagoda and this pagoda, respectively, the modeling of prostrate lions are the most vivid in the three pagodas and the best preserved. The malla statues hold the second set of double upturned lotus in each corner eagle of this waist. There is a layer of octagonal platform in the above of upturned lotus; the above of 
platform is the third set of double upturned lotus. The below scale is the smallest, the second group is middle, and the third group is the largest in the three groups, step by step.

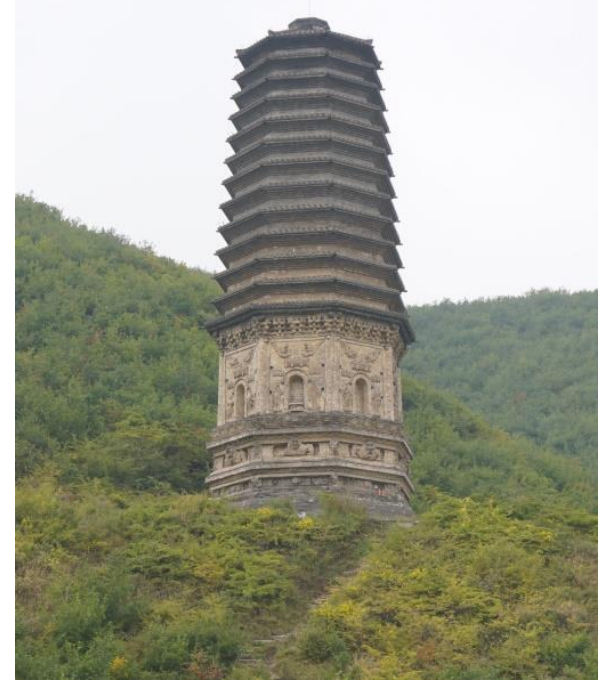

Fig.1 golden pagoda in Shimu Town Haicheng City

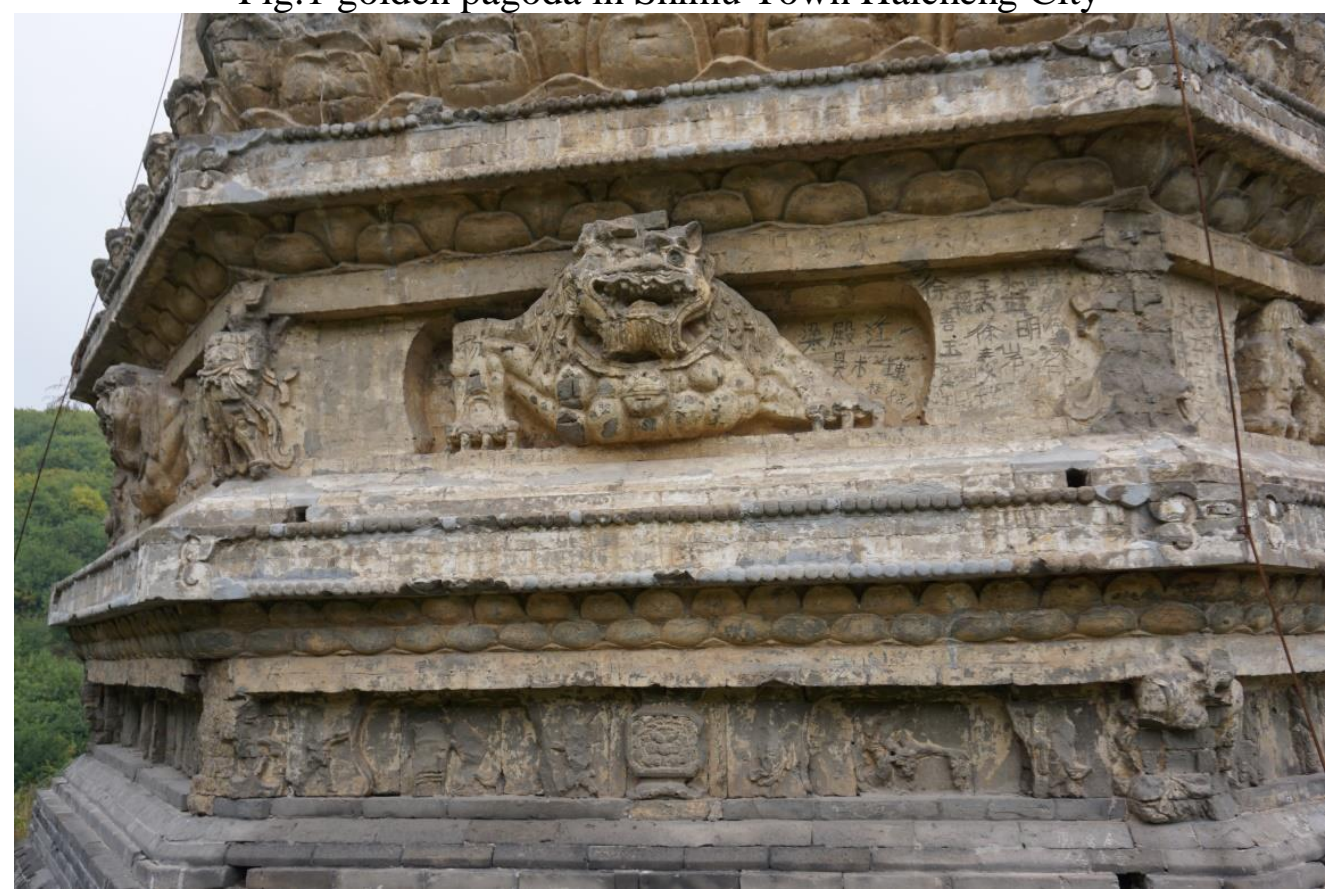

Fig. 2 prostrate lions in base of golden pagoda

The above of base part is the pagoda body. The multi-eaved pagoda is much taller than the other layers of the pagoda. This is the form inherited from Tang Dynasty. The ratio between height a layer of the pagoda body wood-like dougong and the third layer of upturned lotus is about 4: 3 compared with width each side of the pagoda, the middle of pagoda all open arch structure blank door. The inside of the arch door originally worshiped the figure of the Buddha, but they have been destroyed. There are co-Bodhisattvas on both sides of the arch door. The arch doors that worship the Buddha statue and the co-Bodhisattvas all have an umbrella cover, the main umbrella cover is large, co-umbrella cover is small, the position is lower. A pair of Bodhisattvas on both sides of arch door is the same handprint, but Bodhisattvas' handprint of each side is different. Engraver of co-bodhisattvas is fine, body is symmetric, but the head has been destroyed. There is a pair of flying fairies in the above of co-Bodhisattvas umbrella, the shape is very beautiful, the proportion is well-coordinated and well-preserved, can be called a rare art treasures. The flying postures on each side of pagoda are not the same, the change is very rich. There are brick-shaped wood-like cylindrical column in each corner 
of the pagoda. The above of leaning columns column is wood-like architrave and Pubofang. The position of architrave and Pubofang of adjacent two sides of the pagoda cross. Although the brick is imitated, but the head part, the architrave and Pubofang of pagoda are even, integral, imitation wood is very solid. The wood-like dougong above the pagoda is also carved very elaborately. The Shuanghua gong wupu as the dougong, three bracket sets between columns. The middle of the dougong is very unique, with the oblique gong, and its Linggong components are made mandarin ducks gesture to hold square eaves purlin. (See Fig.3) a layer of pagoda with rafters, flying, covered with tile. The height of the pagoda on the second floor is slightly smaller than the first dougong part, the height of each floor eaves in layers, form a diminishing trend. Among all Liao pagoda, the contract of pagoda is modest. The top of the pagoda are damaged, because of the lack of the base, maintenances are not supplemented in recent years.

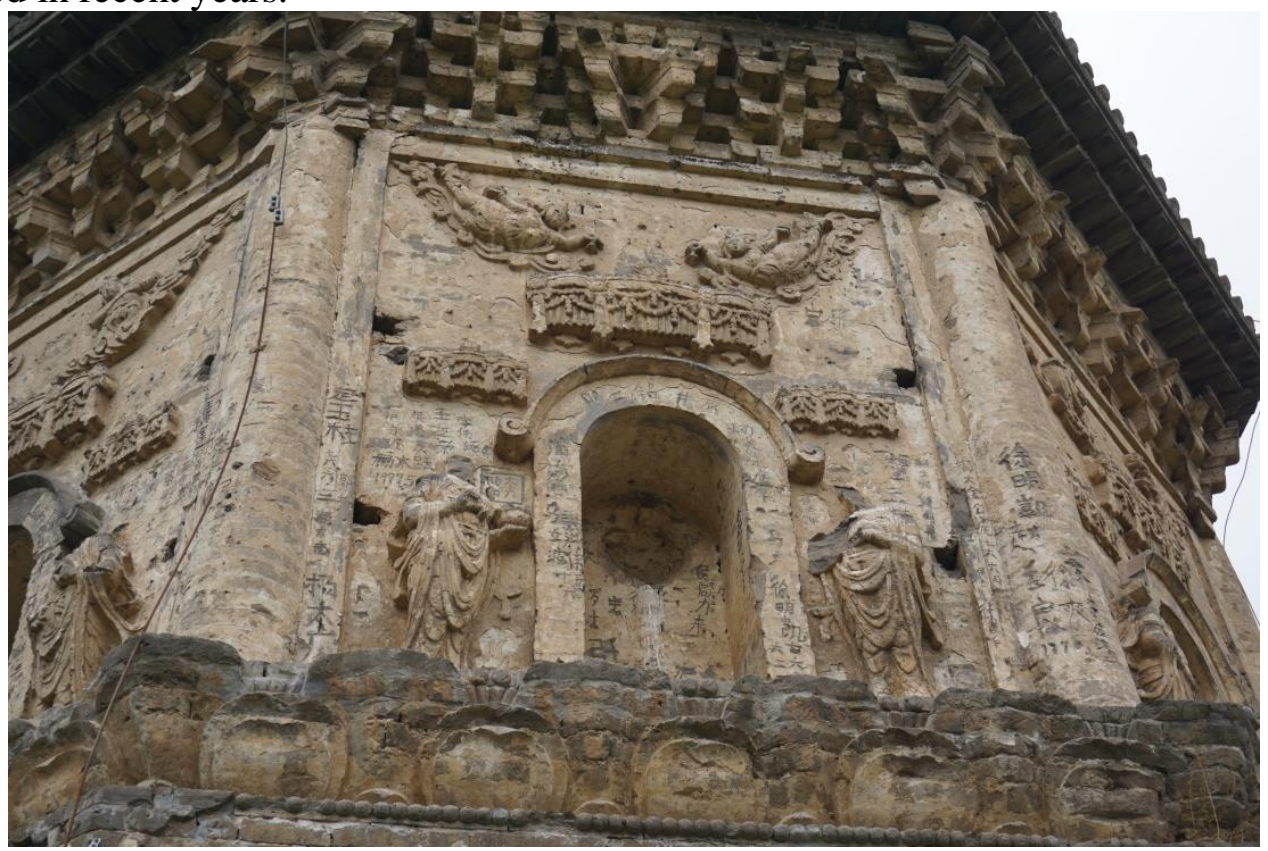

Fig.3 pagoda sculptures of Jin pagoda and imitation wood structure

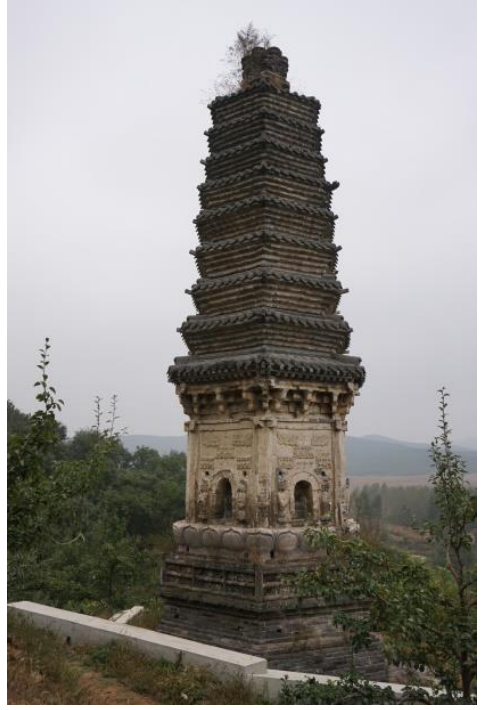

Fig.4 Silver Pagoda in Shimu Town

\subsection{Basic layout of the Shimu silver pagoda}

Silver pagoda is located Tazigou village which is 7.7 kilometers far from northeast of Shimu Town. The height of pagoda is about 15 meters, six-face nine-layer solid multi-eaved pagoda. (See Fig.4) The base part of pagoda is brick simple Xumizuo, it is difficult to find the traces of original structure of the Jin Dynasty after the descendants' previous renovation. The banister and figure of Xumizuo is more fine, it seems that the original. But upturned lotus with huge proportion above the banister also must be added by generations. On the whole, the Xumizuo part of silver pagoda is relatively simple. The width 
and height artio of silver pagoda is similar to golden pagoda, there are arch door in each side of the pagoda, the Buddha statues, but natural damages of statues are more serious. Bodhisattvas are in both sides of door, although several sides are well preserved, but the proportion is jerky, top-heavy, action is dull. The umbrella statue of the lord and the attendants' head is thin, and the flying shape is square, and carving is shallow as well, like a slightly embossed pattern, lacking a three-dimensional effect (see Fig. 5).

The hexagonal square wood-like chair is non-existent in the wood structure, which belong to the solid imitation wood. The architrave and pupaifang cannot be consistent with the head part of pillar. The above imitation wood part is Shuanghua. Bracket sets between columns, dou sculpture is rough, banding method is very small, the above of second bracket without gong, the wood bears the eaves purlin. The eaves square-columns are square head. These are also not solid performance of imitation wood (see Fig. 6). There is no pagoda body above the two or more of pagoda, direct five layers of stacked eaves, the eaves of pagoda slightly contract top upturned lotus, the top of pagoda is damaged and never repaired. Because the body of whole pagoda is relatively thin and short, upward of eaves look like too large, the eaves are too small.

From the whole, the shape of pagoda is relatively thin and slim, but the shape is not graceful, the visual tension of outline is inadequate.

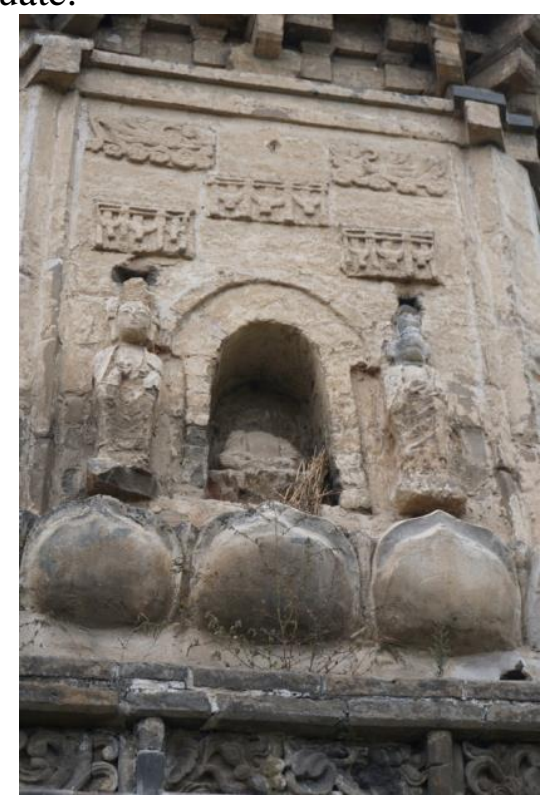

Fig.5 pagoda body sculpture of silver pagoda

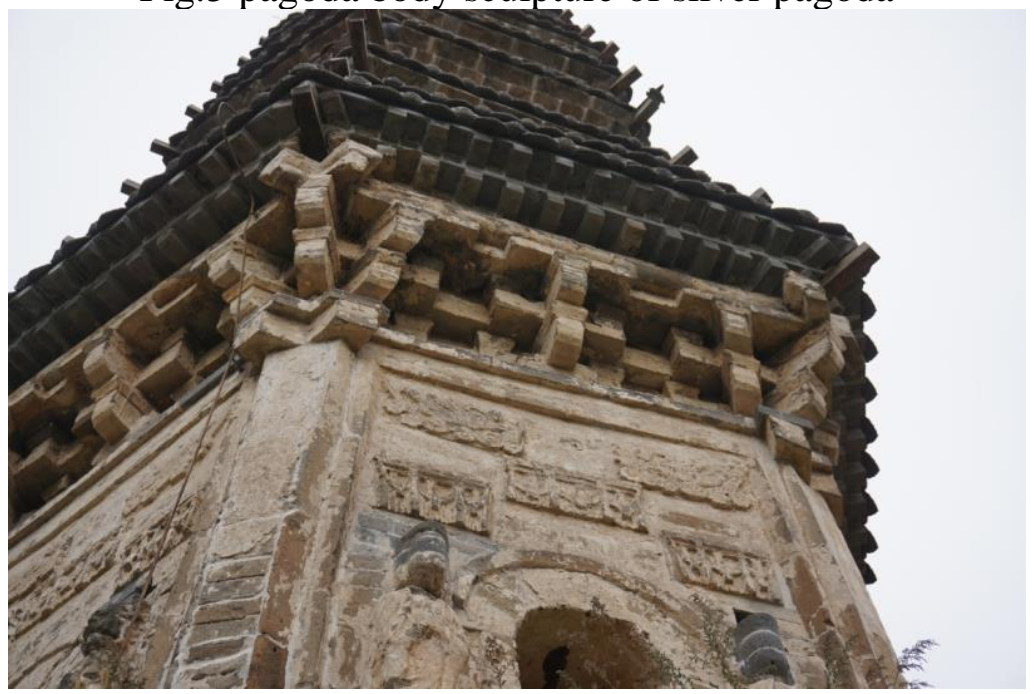

Fig. 6 wood-like structure of the silver pagoda 


\section{Similarities and Differences of Two pagoda modeling.}

Mastering the basic form information of the golden pagoda and silver pagoda, we can compare the form characteristics of the two. More simply, the two pagodas are the northern of multi-eaved brick pagoda; the structures are composed of the pagoda base, pagoda body, pagoda eaves three parts. Above the pagoda is the arch doors, the Buddha are worshiped, servants on the both sides, the above are umbrella and flying fairy. There are wood-like dougong under the first layer of pagoda eaves, although the number of layers above are different, but each layer of eaves have five layers of brick stack, two pagoda eaves have different degrees of contract. In short, there are many similarities between the two. But if we carefully observe, we will find very different between the two pagodas.

From the part of Xumizuo, the complication of golden pagoda is in sharp contrast the simplicity of silver pagoda, but excessive rebuilding factors of the silver pagoda by future generations are not excluded. From the pagoda body, although the aspect ratio of two pagodas is similar, but because the body of the pagoda is a flat hexagon, so a layer of pagoda body looks much thinner than the golden pagoda. The statues and ornaments sculpture of silver pagoda compared with the golden pagoda, the gaps of sculpture level and the detail degree are very obvious. The silver pagoda is completely inferior. Compared the real and detail degree from the pillar, dougong and other wood-like components, the imitation wood of golden pagoda is very strict, realistic and very detailed, maintain their own characteristics in rigor. In contrast, the silver pagoda is not only imitated roughly and lack of component, but also because cantilever of bracket is too small, which cause eaves to be too narrow from the other hand also cause the eaves shape of five-story stacked pagoda not beautiful. Because of high volume, the dense eaves parts of golden appear very harmonious, but because the size is too small and the hexagonal structure of itself, the eaves of the pagoda are inherently less stretched, in addition to the above reasons, eaves seem even more uncoordinated. In this case, the silver pagoda does not reduce the stacking step by step, the ratio relation of pagoda eaves still rigidly adhere to use five-story stacking, causing it to lose the last shape adjustment opportunity. What causes two dense multi-eaved pagodas in the Liao; Jin Dynasty formed such a big difference? This is start from the Buddhism policy of the two dynasties.

\section{Reason Analysis of Different Layout of Pagoda oF Liao, Jin Dynasty}

Buddhism was worshiped by Liao Dynasty, the royalty and the common people revere Buddha to an unprecedented height. The people all over the country take much energy to build pagoda. According to incomplete statistics, the pagodas are built about three hundred or more in the Liao dynasty with two hundred years history. When Kublai Khan and Zhang Dehui talked about the way of governing, they thought "Liao Dynasty is undermined by Buddhism", it is very reasonable. From the emperor to the people all deeply religious in Liao dynasty, there is no utilitarian thought in building pagoda, there are 30 pagodas with 330 meters or more than 30 meters in the existing Liao pagoda, Zhongjing Daming pagoda as high as 80.22 meters. Liao dynasty on the requirements of the pagoda layout is also very delicate and rigorous, several pagoda shape almost form the rules and difficult to break. Until the last years of Liao dynasty, due to the loss of government control and economic reasons, this rule was broken. The layout of the pagoda began to appear more complex change during this period to affect the Jin Dynasty. So layout of Jin pagoda is not as serious as the Liao dynasty, There are reasons for this special change often appear in rules.

Jin Dynasty rulers learned the lesson of Liao Dynasty and advocated moderate principle, that is, made full use of the enlightenment of Buddhism, restricted the excessive Buddhist activities in the policy as well, control the scale of Buddhism. On the other hand, Buddhism is also attached to the rulers, with a significant utilitarian tendency. This makes the pagoda in the volume is limited in Jin Dynasty, the vast majority of the pagoda height are controlled in the 20 meters or so, achieve contract relative to the Liao Dynasty, appear exquisite. This article talked about the height of the golden pagoda and silver pagoda, which is just on behalf of different attitudes to treat the pagoda in the two periods. 
If you compare the Liao pagoda and the Jin pagoda, we will find from the pagoda shape, the traditional Liao pagoda almost all plane octagonal, and most of the Liao pagoda with a layer of relatively thick pagoda body, The characteristics that diameter width is widen than two layers of dense eaves, which makes the visual senses of Liao pagoda more stout. And the Jin pagoda not only appeared in the plane hexagon, but also further shrink the proportion of pagoda base and pagoda body, so that a layer of diameter of the pagoda is basically similar to the two layers of the contract part, or narrower than diameter the two contract part, the Xumizuo parts of the majority of the pagoda are also reduced from the two layers to a layer. Not only the pagoda base, the pagodas appear change, and eaves contracts of most Jin pagoda are smaller, which makes the pagoda slightly tall and thin, top-heavy. Because the Liao Dynasty inherited the language of the Tang Dynasty's Multi-Eaved Pagoda, and develop on the basis, carried out a lot of practice to try, so the pagodas proportion between eaves are carefully pondered and weighed, pagoda height of dense eaves part are carefully elegant. And the Jin pagodas were directly imitate the Liao Dynasty, so contract spacing between the dense eaves were often overlooked, so that the spacing between the eaves smaller than Liao. In addition, because the Liao Dynasty is the inventor of perfect pagoda-shaped rhythm relation, and the Jin Dynasty is only the imitator, shape and quality of pagodas are more dependent on the designer's personal level of the pagoda, which caused the shape differences of Jin pagoda are relatively large, some know how to adapt and adjust to result in innovation, and some are more rigid. This question is also reflected in the comparison of the golden and the silver pagoda. Compared with the golden pagoda, Compared with golden pagoda, the eaves of silver pagoda without pagoda body, and do not know how to adjust the stack shape by increase or decrease the shape of the pagoda eaves. This is the performance that constructor understand the pagoda rigidly.

From the purpose of building pagoda, the majority of Liao pagodas are used to worship Buddha, pray to Buddha, lay Buddha's relics; most of Jin pagodas are used to lay the monks' bone, so the specifications of Jin pagoda are simplified relative to the Liao pagoda. Liao and Jin dynasties embody the different religious connotations. Liao Dynasty directly inherited the atmosphere of Tang Dynasty, Tantric are main, and believe Huayan. So the statue of the Liao Dynasty pagoda take the all directions Buddha as main, fingerprints of statues are accurate, ritual is correct, proportion are symmetrical, beautifully carved, template without word are formed for the believers to learn. Jin Dynasty, such as the Youyu district, most worship Zen, stress epiphany, Buddha statue is less, even if there are the habit of pagoda sculpture statues still in some areas, accuracy of statues and sculpture techniques and ritual are worse relative to the Liao Dynasty. This is reason why we see the silver pagoda sculpture not as good as the golden pagoda sculpture. As for not sturdy wood-like structure of the silver pagoda, the final analysis is also caused by this reason.

\section{Conclusion}

We can summarize the general characteristics in shape of Liao pagoda and Jin pagoda through the above analysis. On the whole, the Liao pagodas are relatively tall, stout, masculine features, sculpture is exquisite, imitation woods are vivid, eaves balance is bigger. But the overall heights of Jin pagoda are not as tall as Liao pagoda, average height is about 20 meters. The shape is thin and delicate, a layer of sculpture is relatively coarse, even most are decorated doors and windows, rather than sculpt statues. The accuracy of the wood-like structure Jin pagoda is lack of consideration. The contracts of Pagoda eaves are generally small and slightly top-heavy. Of course, these are comparison; it is not to say that golden pagodas are completely wrong. In the achievements of a brick multi-eaved pagoda, pagoda of Liao dynasty is the first in history, comparison between the two, Jin pagodas will be eclipsed. In general, quality and aesthetic of Jin pagoda still no less than other historical period.

There is a problem that we should also pay attention to, architects' design and construction methods all does not change soon due to regime change, so we need to know that the above changes are progressive processes in a quite long historical period, if we are deliberately dogmatic, almost every kind of differences can be given disproof examples. For instance, we said that the contracts of golden 
pagoda are usually smaller; this feature is not reflected in Shimu silver pagoda. So if you want to distinguish Jin pagoda and Liao pagoda, in addition to the above methods, the related literatures and features connected with pagoda need to be done detailed research as well, it needs a concrete analysis of specific situations, draw conclusion by seeking truth from facts after repeated consideration.

\section{References}

[1]. Liang Sicheng,"Chinese Architecture History". Baihua Literature and Art Publishing House. 2005.5.

[2]. Liang Sicheng, Liu Zhiping, "Atlas of Chinese Architectural Art, Baihua Literature and Art Publishing House, 2007.1

[3]. Liu Duizhen, Architectural History of Ancient Chinese, China Architecture\& Building Press, 2015.11.

[4]. Zhang Yuhuan, Pagoda of China, Shanxi People's Publishing House, 2000.12.

[5]. Hou YouBin, "Chinese Architectural Aesthetics", Heilongjiang Science and Technology Press, 2000.4 . 